\title{
Percepções paisagísticas como instrumento de Educação Ambiental
}

\section{Janine Farias Menegaes ${ }^{1}$, Toshio Nishijima ${ }^{2}$, Fernanda Alice Antonello Londero Backes ${ }^{3}$ e Cláudia Cisiane Benetti 4}

${ }^{1}$ Universidade Federal de Santa Maria. Curso de Especialização em Educação Ambiental. Avenida Roraima, 1000, Prédio 42. Sala da Direção do Centro. Santa Maria, RS, Brasil (CEP 97105-900). E-mail: janine_rs@hotmail.com.

${ }^{2}$ Universidade Federal de Santa Maria. Departamento de Engenharia Rural. Avenida Roraima, 1000, Prédio 42. Santa Maria, RS, Brasil (CEP 97105-900).

${ }^{3}$ Universidade Federal de Santa Maria. Departamento de Fitotecnia. Avenida Roraima, 1000, Prédio 42. Santa Maria, RS, Brasil (CEP 97105-900).

${ }^{4}$ Universidade Federal de Santa Maria. Departamento de Metodologia do Ensino. Avenida Roraima, 1000, Prédio 42. Santa Maria, RS, Brasil (CEP 97105-900).

Resumo. A Educação Ambiental é múltipla e interdisciplinar, que atribui valores associados à sustentação da vida através dos ecossistemas naturais para fins recreativos, culturais, estéticos, espirituais e simbólicos da sociedade humana. Neste sentido, a valoração da vida é refletida na importância em que os seres humanos atribuem aos componentes do ambiente e suas interações, incluindo suas percepções. Assim, o presente trabalho teve como objetivo valorizar os espaços de convívio em comunidades rurais por meio de percepções paisagísticas atreladas à Educação Ambiental, através de visitas técnicas na zona rural do Município de Faxinal do Soturno, Estado do Rio Grande do Sul, Brasil. Ocorreram nove visitas técnicas a agricultores que foram selecionados por ter participado das oficinas em etapa anterior, e que demonstraram interesse em obter uma renda alternativa com uso das técnicas de paisagismo e jardinagem abordados nas oficinas. Observou-se que seis agricultores buscavam o embelezamento da propriedade, três queriam promover o turismo rural por meio do ajardinamento de suas propriedades, dois gostariam de tornar-se produtores de plantas ornamentais e um buscava promover o comércio de plantas ornamentais. Alguns dos agricultores visitados apresentaram mais de um objetivo, todos atrelados às práticas de paisagismo e jardinagem. Conclui-se que as percepções paisagísticas dos espaços de convívio em comunidades rurais foram valorizadas após a inserção dos conhecimentos relacionados à educação ambiental, despertando a conscientização destes agricultores sobre a sustentabilidade do uso dos recursos naturais de suas propriedades de maneira harmônica com o ambiente.
Recebido

$02 / 07 / 2020$

Aceito

$10 / 04 / 2021$

Disponível on line

$12 / 04 / 2021$

Publicado

$30 / 04 / 2021$

Acesso aberto

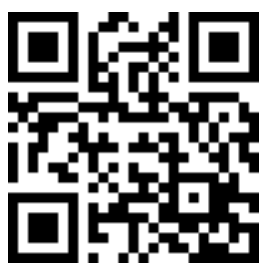

ORCID

0000-0001-6053-4221

Janine Farias

Menegaes

(D) 0000-0002-1892-1065

Toshio Nishijima 
Palavras-chave: Educação interdisciplinar; Remodelação da paisagem; Qualidade de vida.

Abstract. Landscape perceptions as an instrument of Environmental Education. Environmental Education is multiple and interdisciplinary, which attributes values associated with sustaining life through natural ecosystems for recreational, cultural, aesthetic, spiritual and symbolic purposes in human society. In this sense, the appreciation of life is reflected in the importance that human beings attach to environmental components and their interactions, including their perceptions. Thus, the present work aimed to enhance the living spaces in rural communities through landscape perceptions linked to Environmental Education, through technical visits in the rural zone Faxinal do Soturno, Rio Grande do Sul State, Brazil. There were nine technical visits to farmers who were selected for having participation in a previous workshop and who showed an interest in obtaining an alternative income using the landscaping and gardening techniques discussed in the workshops. It was observed that six farmers sought to beautify the property, three wanted to promote rural tourism through landscaping of their properties, two would like to become producers of ornamental plants and one sought to promote ornamental plants trade. Some of the visited farmers had more than one objective, all linked to landscaping and gardening practices. It is concluded that landscape perceptions of living spaces in rural communities were valued after the insertion of knowledge related to environmental education, awakening the awareness of these farmers about the sustainability of the use of natural resources on their properties in harmony with the environment.

Keywords: Interdisciplinary education; Landscape remodeling; Quality of life.
(D) $0000-0003-1064-7847$

Fernanda Alice

Antonello Londero

Backes

D 0000-0001-7063-4242

Cláudia Cisiane

Benetti

\section{Introdução}

A percepção é algo intrínseco, é pessoal, é singular e ao mesmo tempo global, que envolve o ambiente como um todo. Principalmente o de convívio, pois o indivíduo está agindo, interagindo e integrando, em um espaço (território, paisagem, local, cenário) e período de tempo (presente e cronológico). Isto se chama vivência em sociedade que é afetada, tanto positiva como negativamente, pelas escolhas relacionadas à religião, política, economia e cultura, sabendo que a sociedade espaço-temporal está em constante transformação de suas paisagens (cenários) de acordo com os interesses desta sociedade, por isso a percepção do ambiente, também, é mutável (Abbud, 2006; Backes, 2012; Petry, 2014).

A Convenção Europeia da Paisagem, estabelecida na Carta de Florença em 2000, define paisagem como uma parte do território tal qual é percebida pelas populações, cujo caráter resulta da ação de fatores naturais e/ou humanos e de suas inter-relações (Convention Europeenne du Paysage, 2000). 0 olhar humano entende a paisagem como um lance de visão, desta forma, realizou seus primeiros registros pela pintura, com 
técnicas minuciosas de pintores tanto ocidentais como orientais que caracterizavam a paisagem de maneira harmônica, bucólica e natural. Na modernidade as paisagens passaram por (trans)figurações simbólicas, alegóricas e até decorativas, servindo de pano de fundo ao cotidiano que explora a problemática social, econômica, política, religiosa e cultural de uma época (temporal) (Simmel, 2009; Tuan, 2012).

A formação do indivíduo deve considerar a sua relação com o meio ambiente no qual está inserido, considerando também o seu contexto histórico, colocando-o como um ser social e implicado nesse processo (Carvalho, 2004; Tuan, 2012). Neste contexto, a educação ambiental surge com o intuito de despertar a preocupação individual e coletiva para a questão ambiental com uma linguagem de fácil entendimento que contribui para que o indivíduo e a coletividade construam valores sociais, atitudes e competências voltadas para a conservação do meio ambiente (Brasil, 1999; Soares et al., 2007). Ao estabelecer uma relação entre a paisagem e a Educação Ambiental, a conscientização é promovida através do processo participativo. Neste processo, o sujeito atua ativamente no diagnóstico dos problemas ambientais, buscando soluções e tornando-se um agente transformador, desenvolvendo habilidades e atitudes com conduta ética condizente ao exercício da cidadania (Moraes, 2004; Sauvé, 2005a).

O desenvolvimento humano deve ser constante e contínuo, de forma que a interdisciplinaridade o auxilie na sua formação com uma visão global e abrangente do meio em que está inserido. Tanto a sensibilização como a conscientização ambiental ocorram de forma intrínsecas, sendo resultado de uma educação libertadora e, por isso, respeitadora do homem como pessoa (Freire e Nogueira, 1993; Jacobi, 2003). Por esta razão, a área educacional nos tem ensinado que a aprendizagem significa mudanças de comportamento, ou seja, significa dizer que o sujeito só aprende quando se percebe modificado. E, as relações sociais do passado e do presente são representadas por uma estrutura social que estão acontecendo diante dos nossos olhos e que se manifestam através de processos e funções (Rays, 2002; Branco, 2003; Sauvé, 2005a).

Ambientes "embelezados" e reordenados permitem ao contemplador um resgate dos valores culturais e ideológicos, sobretudo, no meio rural, em que a natureza está inserida no seu cotidiano. Deste modo, a utilização de técnicas e práticas paisagísticas e ajardinamento podem propiciar o uso de espécies vegetais e mobiliárias atrativas ao público usuário melhorando os espaços de convivência social (Petry, 2014; Menegaes et al., 2016). Ações educativas, especialmente, sobre percepção ambiental em distintos espaços de convivência, podem cumprir um papel importante sobre as informações e trocas de experiência acerca da Educação Ambiental (Merck, 2008).

Deste modo, o presente trabalho teve como objetivo valorizar os espaços de convívio em comunidades rurais por meio de percepções paisagísticas atreladas à Educação Ambiental, através de visitas técnicas.

\section{Material e métodos}

As visitas técnicas foram realizadas durante o mês de novembro de 2019, no Município de Faxinal do Soturno, Estado do Rio Grande do Sul, sendo parte do projeto de pesquisa intitulado "Educação ambiental por meio de práticas de ajardinamento em espaços de convivência social em comunidades rurais". Ao total realizaram-se nove visitas a agricultores pré-selecionados pelos técnicos da EMATER/RS-ASCAR (Associação Riograndense de Empreendimentos de Assistência Técnica e Extensão Rural), Regional de Faxinal do Soturno, Estado do Rio Grande do Sul. Esses agricultores foram selecionados por ter participado das Oficinas de Paisagismo e Jardinagem, em etapa anterior, e que demonstraram interesse em obter uma renda alternativa com uso das técnicas de paisagismo e jardinagem abordados nas oficinas. 
Para Monezi e Almeida Filho (2005), a realização de visita técnica favorece a sistematização e a vivência das ações relacionadas à prática pedagógica, como da investigação científica, em especial quando atreladas as atividades de educação ambiental.

O Município de Faxinal do Soturno, possui aproximadamente 6.700 habitantes, com área aproximada de $170 \mathrm{~km}^{2}$, abrangendo a sede mais 16 comunidades, localizado na Depressão Central, distando cerca de $45 \mathrm{~km}$ do Município de Santa Maria e $220 \mathrm{~km}$ da Capital Porto Alegre (Figura 1). Apresenta o Índice de Desenvolvimento Humano (IDH, 2010) de 0,720 sendo que o IDH do Brasil foi de 0,759 e do Rio Grande do Sul (RS) foi de 0,746 (IBGE, 2019; SEBRAE, 2019), e o Índice de Desenvolvimento Socioeconômico (IDESE, 2016) de 0,730, esse índice avalia a situação socioeconômica dos municípios gaúchos quanto à educação, à renda e à saúde, considerando aspectos quantitativos e qualitativos do processo de desenvolvimento. O RS atingiu a marca de 0,751 em 2016 (SEBRAE, 2019). 0 município tem sua economia baseada no setor agrícola. Em 2017, as cinco principais culturas produzidas, em hectares, foram o arroz $(48,7 \%)$, soja $(31,6 \%)$, fumo $(8,5 \%)$, milho $(6,5 \%)$ e mandioca $(1,7 \%)$ (IBGE, 2019; SEBRAE, 2019).

As visitas técnicas ocorreram em conjunto com os projetos do Grupo Jardim na Escola, desenvolvidos pela Universidade Federal de Santa Maria (UFSM). 0 Grupo Jardim na Escola é composto por professores, alunos e técnicos administrativos da UFSM, que desenvolvem projetos de pesquisa, ensino e extensão com a temática de educação socioambiental, abordando temas relacionados às técnicas de paisagismo e de jardinagem. Neste trabalho, as visitas ocorrem em parceria com o técnico da EMATER/RS-ASCAR Regional Faxinal do Soturno, RS.

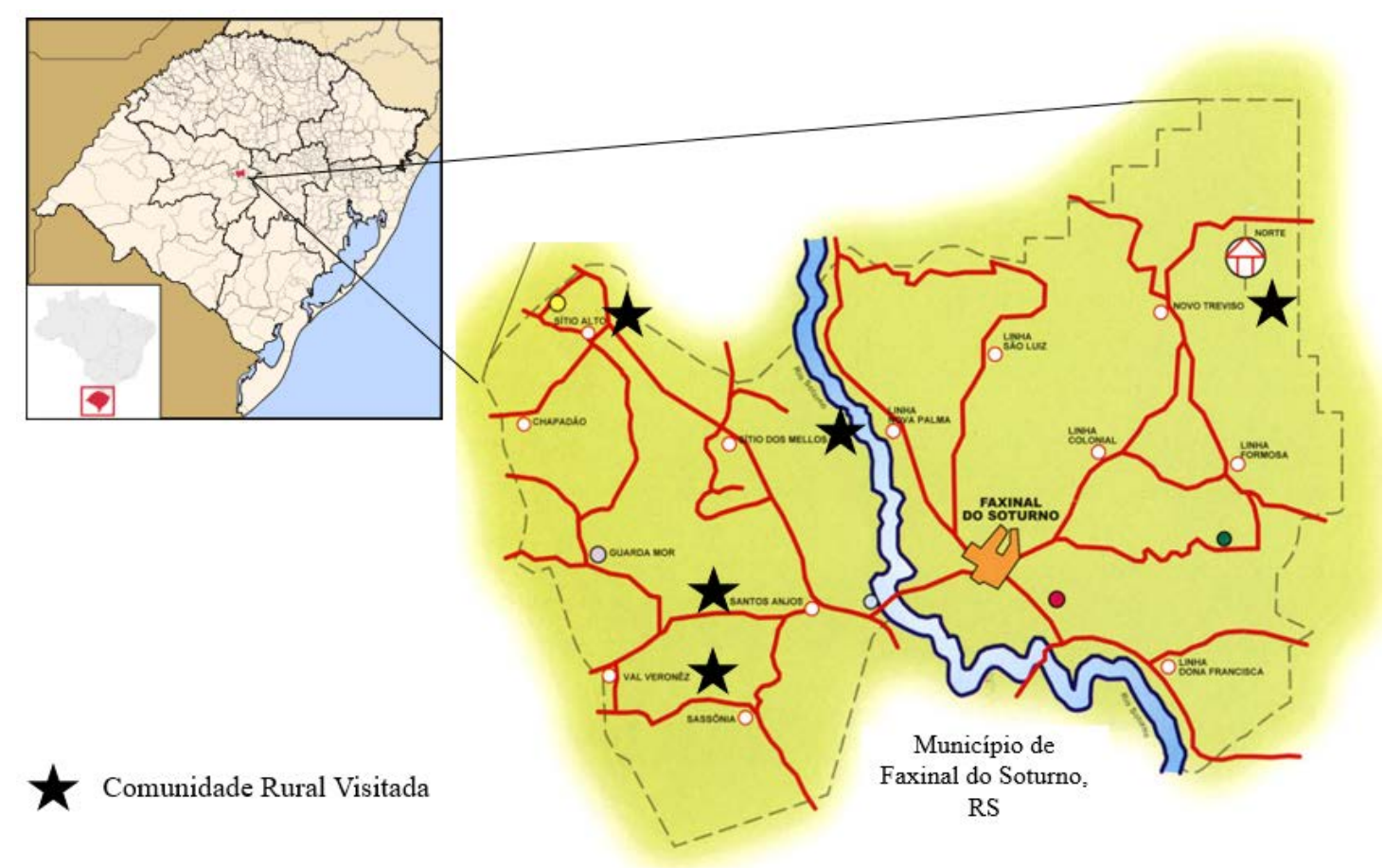

Figura 1. Localização do município de Faxinal do Soturno, RS.

Durante as visitas realizou-se o registro fotográfico e o esclarecimento de dúvidas referentes às técnicas de paisagismo, reconhecimento de plantas de interesse ornamental, usos e manejo das espécies existentes nas propriedades visitadas, quais as finalidades das 
plantas analisadas no jardim, o uso de vasos, entre outros, com uma abordagem sob a ótica da educação ambiental.

\section{Resultados e discussão}

As visitas aos agricultores ocorreram em nove propriedades rurais de diferentes comunidade. A Figura 2 mostra algumas imagens destas visitas. Todos os agricultores participaram das Oficinas de Paisagismo e Jardinagem (etapa anterior ao projeto) e demonstraram interesse de melhorias em suas propriedades ou em obter uma renda alternativa a partir do apresentado durante as oficinas. A Tabela 1 apresenta as descrições dos agricultores e os objetivos que levaram as visitas em suas propriedades.

As primeiras percepções dos agricultores visitados, oito destes do sexo feminino, ao chegar às suas propriedades "todas" falaram a mesma frase "entre e fiquem a vontade, só não repara a bagunça". Contudo, o oposto à fala das agricultoras foi observado, em todas as propriedades, incluindo a casa, a horta e o jardim, estavam impecáveis quanto à organização e limpeza. Neste caso, verificou-se o hábito das mulheres necessitarem de aprovação dos visitantes e não valorizar seu trabalho doméstico. Isso acontece devido à desvalorização das mulheres que trabalham em casa, fazendo os afazeres domésticos, bem como trabalhando de forma a obter uma renda extra.

As visitas aos agricultores, depois da realização das oficinas, possibilitou uma interatividade entre os visitantes e os visitados, a troca de experiência foi mútua. Nestas visitas, verificou-se in loco o conhecimento empírico, que são saberes antigos ou adquiridos por experiência, sobre os cuidados e preocupações com o meio ambiente favorecendo, assim a conversa.
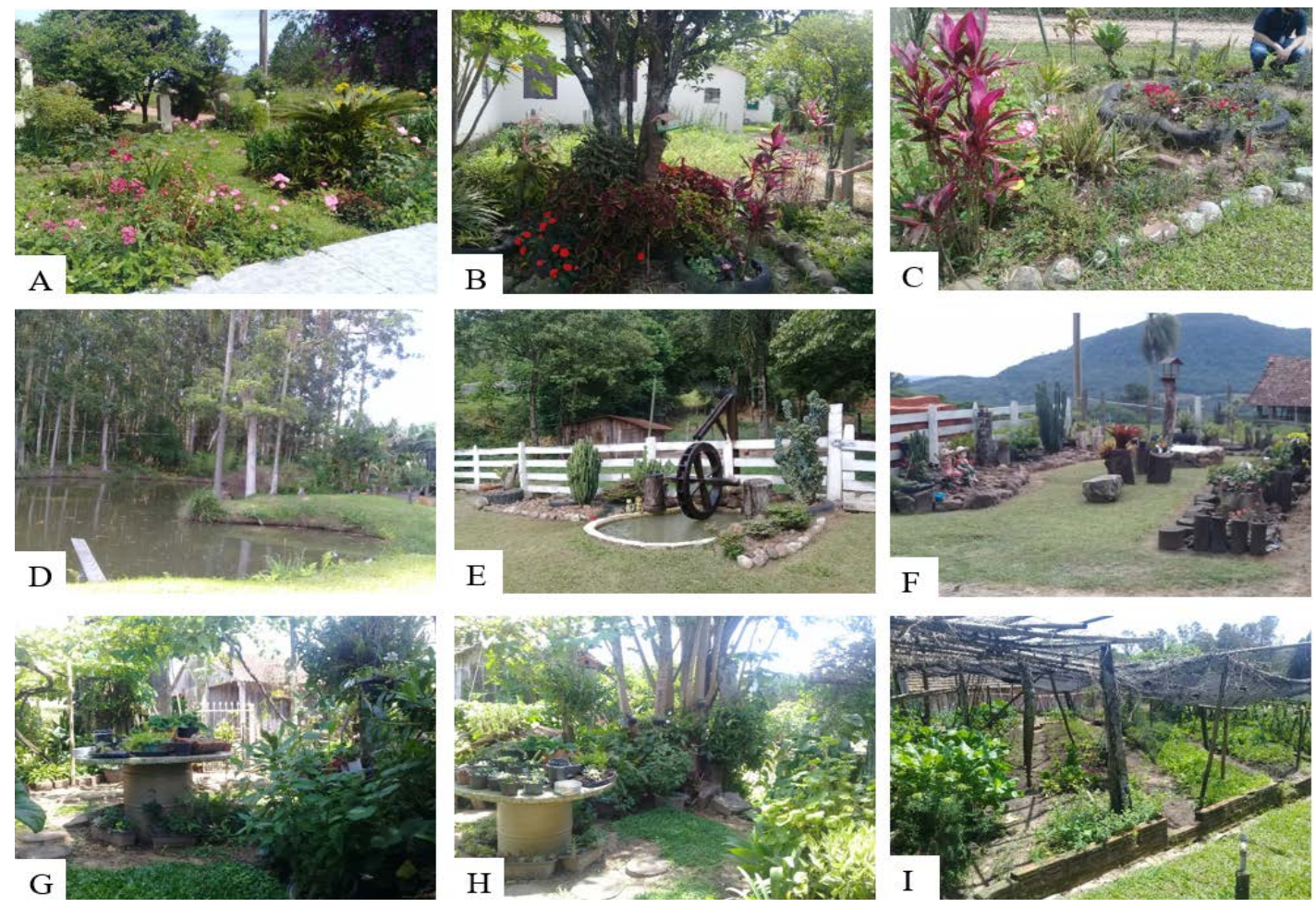

Figura 2. Cenários das propriedades rurais visitas em diferentes comunidades rurais no Município de Faxinal do Soturno, RS. A, B e C: embelezamento da propriedade; D, E e F: promoção do turismo rural na propriedade; G, H e I: produção de mudas ornamentais.

Rev. Bras. Gest. Amb. Sustent., 2021, vol. 8, n. 18, p. 225-234. 
Tabela 1. Visitas realizadas aos agricultores em diferentes comunidades rurais no Município de Faxinal do Soturno, RS.

\begin{tabular}{|c|c|}
\hline Descrição dos agricultores & Objetivo da visita \\
\hline $\begin{array}{l}\text { Colecionadora de plantas ornamentais, sua } \\
\text { propriedade está localizada em uma bifurcação de } \\
\text { acesso a estrada Eremita de São Pio. Produtora de } \\
\text { fumo e hortaliças, e feirante. }\end{array}$ & $\begin{array}{l}\text { Embelezar este ponto promovendo o turismo } \\
\text { rural. }\end{array}$ \\
\hline Colecionadora de orquídeas e produtora rural. & $\begin{array}{l}\text { Torna-se produtora de orquídeas e expor } \\
\text { em feiras da região. }\end{array}$ \\
\hline $\begin{array}{l}\text { Tem coleção de plantas no estilo "jardim da vovó". } \\
\text { Costureira e junto ao marido produzem brinquedos } \\
\text { de madeira e casinhas para passarinhos. }\end{array}$ & $\begin{array}{l}\text { Embelezar sua propriedade como atrativo } \\
\text { para venda dos seus produtos. }\end{array}$ \\
\hline Produtora rural de grãos. & Embelezar suas propriedades. \\
\hline $\begin{array}{l}\text { Costureira e colecionadora de plantas ornamentais, } \\
\text { especialmente suculentas. }\end{array}$ & $\begin{array}{l}\text { Embelezar suas propriedades. } \\
\text { produtora de suculentas e expor em feiras } \\
\text { da região. }\end{array}$ \\
\hline $\begin{array}{l}\text { Produtora de hortaliças e de produtos de } \\
\text { agroindústria (licor, geleias, salames e outros). }\end{array}$ & $\begin{array}{l}\text { Embelezar sua propriedade para converte-la } \\
\text { em pousada rural e ponto de venda de seus } \\
\text { produtos. }\end{array}$ \\
\hline Produtoras rurais de grãos. & Embelezar suas propriedades. \\
\hline $\begin{array}{l}\text { Produz e comercializa bonsai, plantas ornamentais, } \\
\text { pássaros, artesanato e antiguidades. }\end{array}$ & Promover seu ponto comercial de plantas. \\
\hline $\begin{array}{l}\text { Colecionadora de plantas ornamentais, } \\
\text { especialmente suculentas e cactáceas. Produtora de } \\
\text { fumo. }\end{array}$ & $\begin{array}{l}\text { Transformar sua propriedade em ponto } \\
\text { turístico, pousada e bar. }\end{array}$ \\
\hline
\end{tabular}

Na Tabela 1, entre as noves visitas realizadas aos agricultores, seis deles buscavam o embelezamento da propriedade, três gostariam de promover o turismo rural por meio do ajardinamento de suas propriedades, dois tinham a intenção de tornarem produtores de plantas ornamentais e um busca promover o comércio de plantas ornamentais (Figura 2). Verificou-se que alguns dos agricultores buscavam mais de um objetivo depois de realizada a Oficina de Paisagismo e Jardinagem. Para Santos e Fofonka (2015) e Morais e Donaire (2019), cada pessoa atribui a importância ao espaço que ocupa, conforme a sua realidade e condição socioeconômica. Em uma comunidade, a percepção sobre o ambiente e a paisagem podem divergir de acordo com seus interesses.

Observou-se que o termo "embelezar" foi recorrente entre as visitas e, também, houve um retorno satisfatório do que os visitados apreenderam com a Oficina de Paisagismo e Jardinagem, aplicando esses conhecimentos nas suas residências (Figuras 2A, 2B e 2C). De acordo com Backes (2012), a compreensão do que é belo está baseada na paisagem natural, onde o indivíduo vive e atua diretamente no ambiente.

Nos dicionários de língua portuguesa "embelezar" significa tornar belo, enfeitar, ornar. Sendo assim, sinônimo de ornamentar, deriva de "ornamental" que vem do latim e significa "colocar em ordem". Neste contexto, embelezar é o mesmo que colocar em ordem, visto que das nove visitas realizadas, oito foram atendidas por mulheres, sendo elas as responsáveis pela casa quanto aos cuidados domésticos e estéticos (manutenção e jardim). Ou seja, a percepção de embelezar a paisagem em seu em torno, possibilita ao próprio indivíduo o poder de ornamentar ou transformar a "sua paisagem" de convívio, seja para o coletivo ou residencial.

Para Ortigoza (2010) e Petry (2014), a percepção dos sujeitos quando inseridos no ambiente (território no tempo), faz com que a paisagem seja compreendida como algo que favoreça a interação entre elementos naturais e sociais. Conforme Silva et al. (2014), na perspectiva do geógrafo Milton Santos (in memorian), a paisagem é complexa e repleta de 
interações que compõe e (re)organizam um espaço pelas suas junções de formas, funções, estruturas e processos. Já Azevedo e Almeida (2016) dizem que uma visão ambiental mais consciente, perpassa pelo entendimento individual da natureza, para a vida em coletividade. Sauvé (2005a) diz que as concepções do meio ambiente (total, todo, o ser) de forma integrada ao conjunto de dimensões do próprio ambiente.

Entre os três agricultores (Tabela 1) pretendentes ao turismo rural em suas propriedades ocorreu a percepção do ajardinamento da paisagem como principal atrativo (Figuras 2D, 2E e 2F), à visitação em suas propriedades para contemplação da natureza. Para Klein et al. (2011) o turismo rural é caracterizado por um conjunto de atividades realizadas no âmbito da propriedade rural, se favorecendo dos recursos naturais e culturais ali existentes. Em que, a harmonia da paisagem, em especial, sua organização paisagística torna-se um atrativo turístico.

Lira Filho et al. (2001) e Faria et al. (2018), classificam o paisagismo como ferramenta multidisciplinar que engloba a ciência e a arte de forma indissociável, resultando em uma paisagem aprazível. Como ciência, o paisagismo envolve todo e qualquer cuidado relativo as plantas de forma ornamentada, enquanto arte, atribui ao ambiente um valor artístico de embelezamento. Assim, a transformação da paisagem para os agricultores visitados, é demandada naqueles locais com ornamentação e embelezamento como oferta de boas-vindas a quem vai usufruí-lo.

$\mathrm{Na}$ Tabela 1, entre os visitados, duas agricultoras pretendiam produzir plantas ornamentais, especialmente, orquídeas e suculentas, para expor em feiras da região (Figuras 2G, 2H e 2I), e apenas, o único produtor de plantas ornamentais e outras tinha como objetivo promover seu ponto de venda. Observou-se que esses três agricultores nas suas diferentes ambições não apresentam conhecimento técnico de cultivo $\mathrm{e}$ comercialização, assim foi sugerido a EMATER/RS-ASCAR Regional Faxinal do Soturno, RS, um curso visando prestar melhor auxílio a esses agricultores.

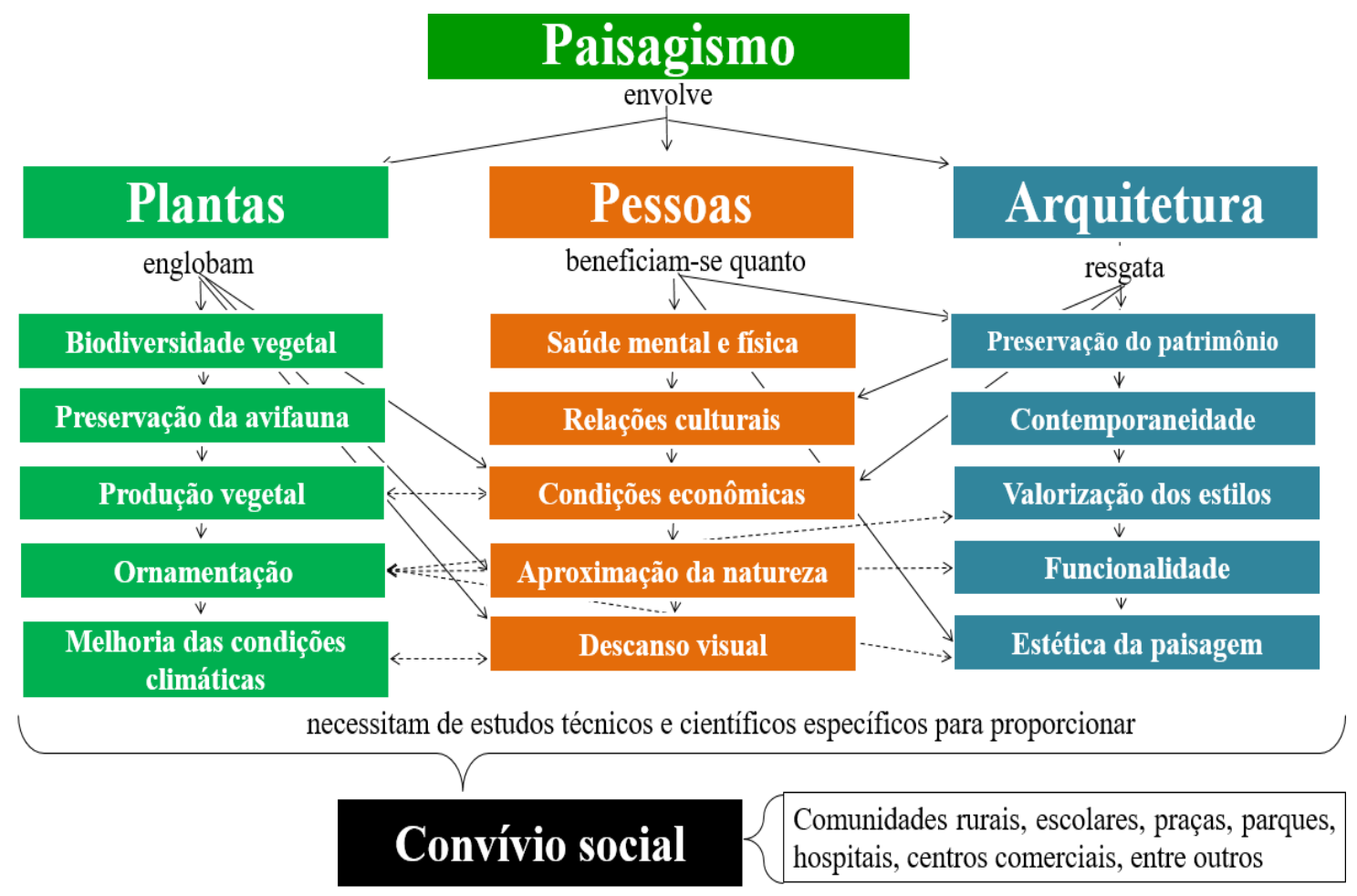

Figura 3. Benefícios do paisagismo para o convívio social. Fonte: Adaptado de Menegaes et al. (2016). 
$\mathrm{Na}$ Figura 3, Menegaes et al. (2016) elencam os benefícios do paisagismo representado por um tripé interativo de plantas-pessoas-arquitetura resultando em um melhoramento dos espaços de convivência social, quer seja pelo embelezamento e valorização da paisagem (cenário local) quer seja pela melhoria das relações humanas da sociedade. Verificou-se que os agricultores presam por qualidade de vida e bem estar, sobretudo, o doméstico.

Jacobi (2003) aponta que há uma constante preocupação com a sustentabilidade planetária, contudo, ocorre uma alta complexidade nas inter-relações entre os sistemas ecológicos e sociais no âmbito de uma comunidade. Para Sauvé (2005b), a abordagem holística da Educação Ambiental possibilita um maior entendimento sobre essa complexidade, utilizando a paisagem como exemplo. Isso ocorre porque essa constitui-se de uma identidade própria e natural tendo interações e integrações mutuas entre os seres habitantes e os elementos da vida (ar, água, solo, outros). Deste modo, Santos e Fofonka (2015) consideram a percepção ambiental uma ferramenta característica da Educação Ambiental para o entendimento sobre a preservação e conservação do ambiente natural, suscitando a conscientização ambiental.

\section{Conclusão}

O conhecimento sobre práticas de paisagismo e jardinagem proporcionam aos visitados uma valorização dos seus espaços de convívio domésticos em comunidades rurais. Desta forma, a percepção ambiental, do indivíduo consciente do seu papel na comunidade, mediado pela educação ambiental possibilita um olhar diferenciado sobre os recursos naturais existentes em sua propriedade, favorecendo seu uso de forma sustentável e harmônica com o ambiente.

\section{Agradecimentos}

A equipe técnica da EMATER/RS-ASCAR (Associação Riograndense de Empreendimentos de Assistência Técnica e Extensão Rural), Regional de Faxinal do Soturno, RS.

\section{Conflito de interesses}

Os autores declaram não haver conflito de interesses.

\section{Referências}

Abbud, B. Criando paisagens: guia de trabalho em arquitetura paisagística. São Paulo: SENAC, 2006.

Azevedo, S. L. M.; Almeida, M. S. P. Concepções espaço-temporal em perspectiva filosófico ambiental no ideário ocidental. SABEH - Ecologias Humanas, v. 4, n. 2, p. 59-82, 2016.

Backes, M. A. T. Paisagismo para celebrar a vida: jardins como cura da paisagem e das pessoas. Porto Alegre: Paisagem do Sul, 2012.

Branco, S. Educação ambiental: metodologia e prática de ensino. Rio de Janeiro: Dunya, 2003.

Brasil. Lei no 9.795, de 27 de abril de 1999. Dispõe sobre a Educação Ambiental, institui a Política Nacional de Educação Ambiental e dá outras providências. Disponível em: <http://www.planalto.gov.br/ccivil_03/leis/19795.htm>. Acesso em: 20 abr. 2019. 
Carvalho, I. C. M. Educação ambiental: a formação do sujeito ecológico. São Paulo: Cortez, 2004.

Convention Europeenne du Paysage. Florence, Italie, Conseil de l'Europe. 2000. Disponível em: <https://www.coe.int/en/web/landscape/home>. Acesso em: 20 nov. 2018.

Faria, R. T.; Assis, A. M.; Colombo, R. C. Paisagismo: harmonia, ciência e arte. Londrina: Mecenas, 2018.

Freire, P.; Nogueira, A. Que fazer? Teoria e prática em educação. Petrópolis: Vozes, 1993.

IBGE - Instituto Brasileiro de Geografia e Estatística. RS - Faxinal do Soturno. 2019. Disponível em: <https://cidades.ibge.gov.br/brasil/rs/faxinal-do-soturno/panorama>. Acesso em: 30 nov. 2019.

Jacobi, P. Educação ambiental, cidadania e sustentabilidade. Cadernos de Pesquisa, v. 1, n. 118, p. 189-205, 2003. https://doi.org/10.1590/S0100-15742003000100008

Klein, A. L.; Troian, A.; Souza, M. O turismo rural pedagógico e a educação ambiental: as ações pedagógicas desenvolvidas na Fazenda Quinta da Estância Grande - Viamão (RS). Revista Eletrônica de Mestrado em Educação Ambiental, v. 27, n. 1, p. 107-121, 2011. https://doi.org/10.14295/remea.v27i0.3197

Lira Filho, J. A.; Paiva, H. N.; Gonçalves, W. Paisagismo: princípios básicos. Viçosa: Aprenda Fácil, 2001.

Menegaes, J. F.; Backes, F. A. A. L.; Rocha, K. M.; Balzan, K. M. Práticas de paisagismo em espaços de convivência social em comunidades rurais e em centro de educação ambiental. Revista Monografias Ambientais, v. 15, n. 1, p. 381-392, 2016. https://doi.org/10.5902/ 2236130819947

Merck, A. M. T. Metodologias interdisciplinares em educação ambiental. Santa Maria: Universidade Federal de Santa Maria, 2008.

Monezi, C. A.; Almeida Filho, C. C. A visita técnica como recurso metodológico aplicado ao curso de engenharia. Anais do XXXII Congresso Brasileiro de Ensino de Engenharia, Campina Grande, 2005. Disponível em: <http://www.abenge.org.br/cobenge/arquivos/ 14/artigos/SP-5-04209359831-1118661953275.pdf>. Acesso em: 22 nov. 2019.

Moraes, M. C. Pensamento eco-sistêmico: educação aprendizagem e cidadania no século XXI. Petrópolis: Vozes, 2004.

Morais, S. F.; Donaire, D. Comunidades intencionais: um estudo sobre dimensões da sustentabilidade em ecovilas paulistas. South American Development Society Journal, v. 5, n. 14, p. 326-346, 2019. https://doi.org/10.24325/issn.2446-5763.v5i14p326-346

Ortigoza, S. A. G. Paisagens do consumo: São Paulo, Lisboa, Dubai e Seul. São Paulo: UNESP, Cultura Acadêmica, 2010.

Petry, C. Paisagens e paisagismo: do apreciar ao fazer e usufruir. Passo Fundo: UPF, 2014.

Rays, $\mathrm{O}$. A. $\mathrm{O}$ conceito de aula: um dos saberes necessários à práxis pedagógica. In: Rays, $\mathrm{O}$. A. (Org.). Educação: ensaios reflexivos. Santa Maria: Pallotti, 2002. p. 84-104.

Santos, D. P.; Fofonka, L. Percepção ambiental e educação ambiental: o uso de mapas mentais. Revista Maiêutica, v. 3, n. 1, p. 17-24, 2015.

Sauvé, L. Educação ambiental: possibilidades e limitações. Educação e Pesquisa, v. 31, n. 2, p. 317-322, 2005a. https://doi.org/10.1590/S1517-97022005000200012

Rev. Bras. Gest. Amb. Sustent., 2021, vol. 8, n. 18, p. 225-234. 
Sauvé, L. Uma cartografia das correntes em educação ambiental. In: Sato, M.; Carvalho, I. C. M. (Orgs.). Educação ambiental: pesquisas e desafios. Porto Alegre: Artmed, 2005b. p. 17-44.

SEBRAE - Serviço de Apoio às Micro e Pequenas Empresas. SEBRAE Perfil Cidades Gaúchas: Faxinal do Soturno. 2019. Disponível em: <https://datasebrae.com.br/ municipios/rs/Perfil_Cidades_Gauchas-Faxinal_do_Soturno.pdf>. Acesso em: 30 nov. 2019.

Silva, E. M.; Marques, A. C. O.; Balsan, R. Paisagem e livro didático: perspectivas filosóficas no ensino de geografia no $6^{\circ}$ ano do Colégio Estadual Marechal Artur da Costa e Silva, Porto Nacional - Tocantins. Interface, v. 1, n. 7, p. 25-37, 2014. https://doi.org/10.1590/ S1517-97022005000200012

Simmel, G. A Filosofia da paisagem. Covilhã: LusoSofia, 2009.

Soares, L. G. C.; Salgueiro, A. A.; Gazineu, M. H. P. Educação ambiental aplicada aos resíduos sólidos na Cidade de Olinda, Pernambuco: um estudo de caso. Revista Ciência e Tecnologia, v. 1, n. 1, p. 1-15, 2007.

Tuan, Y. Topofilia: um estudo da percepção, atitudes e valores do meio ambiente. Londrina: Eduel, 2012.

Informação da Licença: Este é um artigo Open Access distribuído sob os termos da Licença Creative Commons Attribution, que permite uso irrestrito, distribuição e reprodução em qualquer meio, desde que a obra original seja devidamente citada. 